\title{
Severe early childhood caries and social determinants in three-year-old children from Northern Thailand: a birth cohort study
}

\author{
Karl Peltzer ${ }^{1,2,3^{*}}$ and Aroonsri Mongkolchati ${ }^{1}$
}

\begin{abstract}
Background: The purpose of this study was to investigate the prevalence and social risk factors of severe early childhood caries in three-year-old children in Northern Thailand, using a birth-cohort study

Methods: The data utilized in this study were from the prospective cohort study of Thai children (PCTC) from the 28 to 38 weeks gestational age until the children reached the age of 36 months $(N=597)$ in Mueang Nan district, Northern Thailand. Questionnaires were administered at different time points and dental examination was conducted at the age of 3 years of the child.

Results: $44.1 \%$ of the 3 year old children had S-ECC. In multivariate logistic regression analysis, environmental factors (the use of rain or well water as drinking water, no schooling of mother of child, being male), and risk behaviour (sleeping with a bottle at 30 months) were associated with S-ECC. Further, in bivariate analysis, psychological distress in the mother, lack of spousal relationship support, suckle to sleep when going to bed, introduction of soft drinks at 12 months, having had more frequently sweet food, and less than daily tooth brushing before 30 months were associated with S-ECC.
\end{abstract}

Conclusions: A very high rate of S-ECC was observed, and oral health may be influenced by social factors.

Keywords: Severe early childhood caries, Preschool children, Social determinants, Thailand

\section{Background}

"Severe early childhood caries (S-ECC) affects infants and children. It is infectious, has a multifactor etiology and fast development, starting soon after dental eruption. Due to the presence of local sociocultural risk factors, it must be regarded as a symptom of alteration in the child's health and lack of adequate care." ([1], p.295) Globally, there is a lack of studies investigating the prevalence and socio-environmental and behavioural risk factors of S-ECC in pre-school aged children [2], and there is little information available in Thailand about the prevalence and socio-environmental and behavioural risk factors of $\mathrm{S}$-ECC in pre-school aged children. Identification of

\footnotetext{
* Correspondence: karl.pel@mahidol.ac.th

'ASEAN Institute for Health Development, Madidol University, Salaya,

Phutthamonthon 73170, Nakhonpathom, Thailand

${ }^{2}$ Department of Psychology, University of the Free State, Bloemfontein 9300

South Africa

Full list of author information is available at the end of the article
}

characteristics associated with children's risk of developing S-ECC may improve preventive strategies.

The prevalence of S-ECC in pre-school age children ranged from $0.8 \%$ (6-71 months) in Nigeria [3], $2.7 \%$ (36-71 months) in Italy [4], $6.5 \%$ (3 year-olds) in Lithuania [5], $9.5 \%$ (3-5 years) in Germany [2], $17.5 \%$ (3-5 years old) in Trinidad [6], $27 \%$ (2 year-olds) in a sample of African Americans [7], 31.1\% (5-6 years) in Ajman, United Arab Emirates [8], 36 \% (35-71 months old) in a health facility in Brazil [9], 46 \% (2-6 years) in the Inuvik region, Northwest Territories, Canada [10], and $56 \%$ (mean age 42 months) in Cambodia [11].

Factors associated with S-ECC have been identified in terms of 1) environmental risk factors, including lack of community water fluoridation [10], Body Mass Index (BMI) overweight [12], and maternal caries experience [11]; 2) sociocultural risk factors, including low socioeconomic status $[8,10,13,14]$, and being a single working mother [15]; 3) risk behaviours, including 
feeding and eating patterns such as excessive sugar intake $[13,14,16,17]$; high snack consumption level [8, 13], breastfeeding $\geq 7$ times daily [13], night-time breastfeeding [9], breastfeeding for more than 12 months [2, 4]; improper infant bottle-feeding habits (use of the nursing bottle in bed [2]; bottle use for liquids other than milk [13]; sleeping with a bottle containing carbohydrates during the night [4]; use of a bottle at night as a substitute for the pacifier and its use on demand during the day $[9,18]$; Low-frequency toothbrushing and improper toothbrushing methods $[4,19]$, start of tooth brushing after the first anniversary [2] and 4) use of dental services [2] and those who utilised dental services only when they had a problem [8]. In this study, we explore associations between environmental factors, sociocultural factors, risk behaviours during pregnancy and the child's early life, and the S-CCC of 3-year-old children in Northern Thailand using longitudinal data. Based on previous studies, it was hypothesized that socio-environmental factors and risk behaviours during pregnancy and the child's early life were associated with S-ECC.

\section{Method}

\section{Sample and procedure}

The data utilized in this study were from the prospective cohort study of Thai children (PCTC) (Data are available from http://pctc.damus.in.th/damus/), which is an observational, community-based study designed to follow all foetuses from the 28 to 38 weeks gestational age until the children reached the age of 36 months [20]. A sample of the Thai population was achieved in four cohort from a selected district in each of the four regions in Thailand [20]. All pregnant women who resided or planned to bring up their children in the four selected districts and who expected to give birth during the defined period of 1 year were registered [20]. The women were identified in the beginning of the third trimester by a community survey or by retrieval from registers of antenatal care clinics [20]. The children who were eligible for the PCTC project with parental consent during pregnancy were sampled for inclusion in the present study and the time of measurement was every 6 months. Questionnaires were interviewed-administered at participants' homes, or at health facilities where parents took their 6 month old infants for immunizations [20, 21]. Dental exam data was collected in three sites, and from one site in Northern Thailand data were available for this study. Therefore, the present study included a subsample of children from Mueang Nan district in Nan province, Northern Thailand. In the study area $13 \%$ of the population are mountain-dwelling tribal people [20]. Buddhism is the predominant faith (84 \%) and most people work in businesses and small farms, sales, services or labour [20]. There is a lower-than-standard level of fluoride in the community drinking water [21]. Dental care is only available at the district hospital. In all, 783 infants were recruited, which was a response rate of $99 \%$ from all contacted families and for 597 children dental caries data were available at the age of 36 months, which is a response rate of $76.2 \%$. This study was approved by the National Ethics Committee of the Ministry of Public Health of Thailand. All families were clearly informed of all the study procedures and possible risk before signing the consent form [22].

\section{Measures}

\section{Dental caries}

The outcome variables were the number of decayed, filled and missing teeth (dmft) and surfaces (dmfs) assessed when the children were 3 years of age. Three trained and calibrated examiners in a field setting examined dental caries. The examiners evaluated dental caries by using decayed, filled and missing primary teeth (DMFT) index and surfaces (DMFS) indices following the World Health Organization [23] criteria for dental caries diagnosis. The dental status of the examined surfaces were classified as follows: $U=$ Unerupted surface, no part of the surface emerges to the oral cavity; $\mathrm{S}=$ Normal enamel surface/texture and no restoration; D1 = Initial caries/acries limited in enamel, the lesion demonstrates whitish/yellowish opaque with/without mico-cavity but no softened floor/ wall; D2 = Caries to dentine, cavitated lesion is seen to extend beyond enamel that certainly catches the probe with softened floor or wall of undermined enamel; D3 = Caries involving pulp; a deep lesion with probable pulpal involvement or deep lesion with present/history of spontaneous pain/swelling/fistula opening [23]. The outcome of this study was S-ECC, defined as $\geq 1$ cavitated, missing or filled smooth surfaces in primary maxillary anterior teeth, or decayed, missing or filled surface (dmfs) values $\geq 4$ [24].

\section{Environmental risk factors}

Anthropometric measurements were assessed according to recumbent length and were measured in all children at 6 and 36 months of age using a graduate board with a fixed headboard and movable footboard $(1 \mathrm{~m} / 0.1 \mathrm{~cm})$ [22].

Infant's birth weight was assessed after birth.

Tobacco use of the mother and history of dental cavitation(s) of the mother were assessed at $28^{\text {th }}$ to $38^{\text {th }}$ week of pregnancy by self-report; and environmental tobacco use and the source of the type of household drinking water were assessed at 6 months of the study infant [22].

\section{Sociocultural risk factors}

Sociodemographic information obtained at $28^{\text {th }}$ to $38^{\text {th }}$ week of pregnancy included parity, parental age, religion, education, household income, family size, birth order, and 
Table 1 Sample characteristics of the overall sample $(n=597)$ and S-ECC sub-sample $(n=263)$

\begin{tabular}{|c|c|c|}
\hline \multirow[t]{2}{*}{ Variables } & \multirow{2}{*}{$\begin{array}{l}\text { All } \\
N=597(\%) \text { or M } \\
\text { (SD) }\end{array}$} & \multirow{2}{*}{$\begin{array}{l}\text { S-ECC } \\
N(\%) \text { or } \mathrm{M} \\
\text { (SD) }\end{array}$} \\
\hline & & \\
\hline Environmental risk factors & $N(\%)$ & $N(\%)$ \\
\hline \multicolumn{3}{|l|}{ Drinking water in household } \\
\hline Bottled & $211(35.4)$ & $88(41.7)$ \\
\hline Pipe & $138(23.2)$ & $56(40.6)$ \\
\hline Rain & $41(6.9)$ & $22(53.7)$ \\
\hline Well or other & $206(34.6)$ & $96(46.6)$ \\
\hline \multicolumn{3}{|l|}{ Weight at birth } \\
\hline$\geq 2500 \mathrm{~g}$ & $529(92.0)$ & $234(44.2)$ \\
\hline$<2500 \mathrm{~g}$ & $46(8.0)$ & $20(43.5)$ \\
\hline Smoking during pregnancy & $2(0.4)$ & 0 \\
\hline Secondary smoke (at 1 year) & $158(26.5)$ & $76(48.1)$ \\
\hline \multirow{2}{*}{$\begin{array}{l}\text { Mother with dental cavitation(s) at } \\
\text { baseline }\end{array}$} & $332(66.5)$ & $151(45.5)$ \\
\hline & $M(S D)$ & $M(S D)$ \\
\hline Height in cms at 6 months [M, SD] & $64.8(2.6)$ & $64.9(2.4)$ \\
\hline $\begin{array}{l}\text { Body Mass Index (BMI) score at } 3 \text { years } \\
\text { [M, SD] }\end{array}$ & $20.9(2.9)$ & $20.8(2.9)$ \\
\hline Sociocultural risk factors & $N(\%)$ & $N(\%)$ \\
\hline \multicolumn{3}{|l|}{ Mother's age at child's birth (in years) } \\
\hline $14-19$ & $64(10.7)$ & $30(46.9)$ \\
\hline $20-24$ & $134(22.5)$ & $67(51.0)$ \\
\hline $25-48$ & $398(66.8)$ & $166(41.7)$ \\
\hline \multicolumn{3}{|l|}{ Mother's schooling at child's birth } \\
\hline None & $82(13.8)$ & $24(29.3)$ \\
\hline Primary & $184(31.0)$ & $99(53.8)$ \\
\hline High school & $169(28.5)$ & $91(53.8)$ \\
\hline Post-high school & $159(26.8)$ & $49(30.8)$ \\
\hline \multicolumn{3}{|l|}{ Household income (in Thai Baht) } \\
\hline $0-49,999$ & $216(36.4)$ & $102(47.2)$ \\
\hline $50,000-99,999$ & $116(19.6)$ & $69(59.5)$ \\
\hline $100,000-199,999$ & $129(21.8)$ & $52(40.3)$ \\
\hline 200,000 plus & $132(22.3)$ & $37(28.0)$ \\
\hline \multicolumn{3}{|l|}{ Religious affiliation } \\
\hline Muslim and other & $83(14.0)$ & $29(34.9)$ \\
\hline Buddhist & $511(86.0)$ & $233(45.6)$ \\
\hline Single parent & $216(36.2)$ & $94(43.5)$ \\
\hline \multicolumn{3}{|l|}{ Family size } \\
\hline $2-4$ & $230(38.6)$ & $109(47.4)$ \\
\hline $5-6$ & $233(39.1)$ & $108(46.4)$ \\
\hline 7 or more & $133(22.3)$ & $45(33.8)$ \\
\hline \multicolumn{3}{|l|}{ Sex of child } \\
\hline Female & $298(49.9)$ & $115(38.6)$ \\
\hline Male & $299(50.1)$ & $148(49.5)$ \\
\hline
\end{tabular}

Table 1 Sample characteristics of the overall sample $(n=597)$ and S-ECC sub-sample $(n=263)$ (Continued)

\begin{tabular}{lll}
\hline First child in family & & \\
No & $342(66.0)$ & $147(43.0)$ \\
Yes & $176(34.0)$ & $84(47.7)$ \\
\hline M Mean; SD Standard deviation &
\end{tabular}

M Mean; SD Standard deviation

marital status. The study infant's sex was recorded after birth.

\section{Risk behaviours}

Information concerning infant feeding practices such as breast, formula, and complementary feeding was assessed in the diary developmental record from birth to 12 months and 30 months of age [22]. One sweet food consumption index was created with five items, sweet jelly, sweet drink, sweet candy, sweet Thai dessert and snack consumption at 30 months. Cronbach alpha was 0.68 for this sweet food consumption index of this sample.

Tooth brushing behaviour was assessed at 12 and 26 months of the study child.

Use of oral services was assessed at 30 months of the study child.

\section{Data analysis}

Data were analysed using the SPSS software package (PASW Statistics 21, IBM Company, 2013). Descriptive statistics were used to describe the sample. We used univariate logistic regression, followed by multivariate backward conditional logistic regression to obtain adjusted odds ratios (AOR) and associated $95 \%$ confidence intervals. All variables with a univariate test $P$ value $\leq 0.25$ were considered for inclusion in the multiple logistic regression models. The level of statistical significance was a twosided $p$ value $<0.05$. Variance inflation factor (VIF) and tolerance values for each model indicate multicollinearity was not a concern in any of the multivariate analyses.

\section{Results}

\section{Sample characteristics}

The total sample size of children recruited from Mueang Nan district with dental caries data was 597. The prevalence of children with severe early childhood dental caries (S-ECC) was $263(44.1 \%)$ at 36 months. The prevalence of ECC was $68.5 \%$. Further sample characteristics are described in Tables 1 and 2 .

\section{Associations with severe early childhood dental caries}

In bivariate analysis, environmental risk factors (the use of rain or well water as drinking water and secondary smoke), sociocultural risk factors (no schooling of mother of child, being male, lower household income, and being a Buddhist), and risk behaviours (never have 
Table 2 Sample characteristics of overall sample $(n=597)$ and S-ECC sub-sample $(n=263)$

\begin{tabular}{|c|c|c|}
\hline \multirow[t]{2}{*}{ Variables } & All & S-ECC \\
\hline & $N(\%)$ & $N(\%)$ \\
\hline \multicolumn{3}{|l|}{ Risk behaviour } \\
\hline \multicolumn{3}{|l|}{ Infant feeding at 6 months } \\
\hline Never breast fed & $295(49.6)$ & $145(49.2)$ \\
\hline Breast feeding: 1-3 months & $155(26.1)$ & $55(35.5)$ \\
\hline Breast feeding: 4 months or more & $145(24.4)$ & $62(42.8)$ \\
\hline \multicolumn{3}{|l|}{ Nocturnal feeding at 12 months } \\
\hline Suckle to sleep when going to bed & $563(94.5)$ & $251(44.6)$ \\
\hline \multicolumn{3}{|l|}{ Introduction of soft drinks at 12 months } \\
\hline None & $289(49.1)$ & $113(39.1)$ \\
\hline $6-12$ months & $299(50.9)$ & $144(48.2)$ \\
\hline \multicolumn{3}{|l|}{ Sleeps with bottle at 30 months } \\
\hline No & $454(76.2)$ & $187(41.2)$ \\
\hline 1-6 times/week & $142(23.8)$ & $76(53.5)$ \\
\hline $\begin{array}{l}\text { Sweet food index in days in a } \\
\text { week at } 30 \text { months }(1-5)\end{array}$ & $2.1(1.3)$ & $2.3(1.2)$ \\
\hline $\begin{array}{l}\text { Brushing teeth in the past } 2 \text { weeks } \\
\text { at } 12 \text { months }\end{array}$ & $345(58.3)$ & $160(46.4)$ \\
\hline Brush with tooth paste at 12 months & $10(2.9)$ & $3(30.0)$ \\
\hline \multicolumn{3}{|l|}{ Brushing teeth at 26 months } \\
\hline At least once daily & $160(31.7)$ & $147(36.4)$ \\
\hline Less than daily & $345(68.3)$ & $84(63.6)$ \\
\hline Use of fluoride tooth paste in past 7 days & $477(88.8)$ & $220(89.8)$ \\
\hline \multicolumn{3}{|l|}{ Use of oral health services } \\
\hline Dental visit before age of 30 months & $41(6.9)$ & $23(56.1)$ \\
\hline
\end{tabular}

GHQ General Health Questionnaire

breast fed the child, suckle to sleep when going to bed, introduction of soft drinks at 12 months, sleeps with the bottle at 30 months, having had more frequently sweet food, brushing teeth at 12 months and less than daily tooth brushing before 30 months) were associated with S-ECC. In multivariate logistic regression analysis, socio-environmental factors (the use of rain or well water as drinking water, no schooling of mother of child, being male), and risk behaviour (sleeping with a bottle at 30 months) were associated with S-ECC (see Table 3).

\section{Discussion}

The study found a high prevalence of severe caries at 36 months of age $(44.1 \%)$ in Northern Thailand, which is higher than in almost all previous studies on S-ECC [2-11]. In previous studies in Thailand also a very high prevalence of dental caries was found among children of 18 months (68.1\%) [25], and among preschool children (95.4 \%) [26]. Less than $10 \%$ of the sample had ever attended a dental visit before the age of 30 months. This may mean that that for a large group or pre-school aged children dental caries remained untreated. Increased preventive measures of the dental public health services targeting infants and pre-school children seem warranted, and early dental attendance, by 12 months of age, to enable anticipatory guidance of caries risk assessment and early management of dental problems [6].

The study investigated social factors for S-ECC in 3 year old the children.

In agreement with previous studies on S-ECC in preschool children $[2,8,10,13,14]$, this study found that lower socioeconomic status (no schooling of mother of child), risk behaviour (sleeping with a bottle at 30 months), and sub-optimal fluoridation of water supply (using drinking water from the rain in the household) were associated with S-ECC. Frequent sleeping with a bottle may increase caries development, since "low salivary flow rate during sleep time in infants decreases oral clearance and increases contact time of plaque and substrates." ([4],p.139). Further, in agreement with a number of studies [13, 14, $16,17]$ excessive sugar intake (introduction of soft drinks at 12 months, having had more frequently sweet food) were found in bivariate analysis associated with S-ECC. "Increased frequency of sugar consumption increases the 
Table 3 Association between environmental, sociocultural, behavioural, dental care and severe early childhood caries

\begin{tabular}{|c|c|c|}
\hline \multirow[t]{2}{*}{ Variable } & \multicolumn{2}{|c|}{ Severe early childhood caries } \\
\hline & UOR (95\% Cl) & $\mathrm{AOR}^{\mathrm{a}}(95 \% \mathrm{Cl})$ \\
\hline \multicolumn{3}{|l|}{ Environmental risk factors } \\
\hline Drinking water in the household: Rain, well or other (base = Bottled or pipe) & $1.30(0.94-1.81)^{* * * *}$ & $1.52(1.00-2.33)^{*}$ \\
\hline Low birth weight $(<2500 \mathrm{~g})($ base $=\geq 2500 \mathrm{~g})$ & $0.97(0.53-1.78)$ & - \\
\hline Height in $\mathrm{cms}$ at 6 months & $1.01(0.95-1.08)$ & - \\
\hline BMI score at 3 years & $0.98(0.92-1.03)$ & - \\
\hline Smoking during pregnancy (base $=$ no) [too few cases $]$ & $1.24(0.08-19.99)$ & - \\
\hline Secondary smoke (at 1 year) $($ base $=$ no) & $1.26(0.87-1.81)^{* * * *}$ & - \\
\hline Mother with dental cavitation(s) at baseline (base $=$ none) & $1.05(0.72-1.52)$ & - \\
\hline \multicolumn{3}{|l|}{ Sociocultural risk factors } \\
\hline \multicolumn{3}{|l|}{ Mother's age at child's birth (in years) } \\
\hline $14-19$ & 1.00 & - \\
\hline $20-24$ & $1.13(0.62-2.06)$ & \\
\hline $25-48$ & $0.81(0.48-1.38)$ & \\
\hline \multicolumn{3}{|l|}{ Mother's schooling at child's birth } \\
\hline None & 1.00 & 1.00 \\
\hline Primary & $2.82(1.61-4.91)^{* * *}$ & $2.06(1.24-3.42)^{* *}$ \\
\hline High school & $2.82(1.61-4.95)^{* * *}$ & $2.21(1.32-3.71)^{* *}$ \\
\hline Post-high school & $1.08(0.60-1.93)$ & $1.04(0.45-2.54)$ \\
\hline \multicolumn{3}{|l|}{ Household income (in Thai Baht) } \\
\hline $0-49,999$ & 1.00 & - \\
\hline $50,000-99,999$ & $1.64(1.04-2.59)^{*}$ & \\
\hline $100,000-199,999$ & $0.76(0.49-1.17)^{* * * *}$ & \\
\hline 200,000 plus & $0.44(0.27-0.69)^{* * *}$ & \\
\hline Religious affiliation: Buddhist (base $=$ Muslim and other) & $1.56(0.96-2.53)^{* * * *}$ & - \\
\hline Single parent (base $=$ not) & $0.97(0.69-1.36)$ & - \\
\hline Family size & $0.94(0.88-1.01)$ & - \\
\hline Sex of child: Male (base $=$ female) & $1.56(1.13-2.11)^{* *}$ & $1.68(1.11-2.53)^{*}$ \\
\hline First child in family (base $=$ no) & $1.21(0.84-1.75)$ & - \\
\hline \multicolumn{3}{|l|}{ Risk behaviour } \\
\hline \multicolumn{3}{|l|}{ Infant feeding at 6 months } \\
\hline Never breast fed & 1.00 & 1.00 \\
\hline Breast feeding: 1-3 months & $0.57(0.38-0.85)^{* *}$ & $0.63(0.38-1.04)$ \\
\hline Breast feeding: 4 months or more & $0.77(0.52-1.15)^{* * * *}$ & \\
\hline \multicolumn{3}{|l|}{ Nocturnal feeding at 12 months } \\
\hline Suckle to sleep when going to bed & $1.61(0.77-3.38)^{* * * *}$ & - \\
\hline Introduction of soft drinks at 12 months: 6-12 months (base = none) & $1.45(1.04-2.01)^{*}$ & - \\
\hline Sleeps with bottle at 30 months: 1-6 times/week (base $=$ no) & $1.64(1.13-2.40)^{* *}$ & $1.79(1.10-2.92)^{*}$ \\
\hline Sweet food index in days in a week at 30 months: $3-7$ times (base $=0-2$ times) & $1.23(1.08-1.41)^{* *}$ & - \\
\hline Brushing teeth in the past 2 weeks at 12 months (base = no) & $1.25(0.90-1.74)^{* * * *}$ & \\
\hline Brush with tooth paste at 12 months (base $=$ no) & $1.20(0.70-2.07)$ & \\
\hline
\end{tabular}


Table 3 Association between environmental, sociocultural, behavioural, dental care and severe early childhood caries (Continued)

\begin{tabular}{|c|c|}
\hline Brushing teeth at 26 months: Less than daily (base $=$ At least once daily) & $1.49(1.02-2.17)^{*}$ \\
\hline Brushing teeth at 26 months with fluoride tooth paste (base = no) & $1.20(0.70-2.07)$ \\
\hline \multicolumn{2}{|l|}{ Use of oral health services } \\
\hline Dental visit before 30 months of age (base $=$ no) & $1.68(0.89-3.18)$ \\
\hline
\end{tabular}

risk of enamel demineralization and decreases time for remineralization by saliva." ([4],p.139) Moreover, as found in previous studies, low-frequency tooth brushing and improper tooth brushing methods [4, 19] (less than daily tooth brushing before 30 months) were associated in bivariate analysis with S-ECC. An important preventive target should be to educate pregnant women or women with infants on avoidance of caries-promoting behaviours [2], such as the use of nursing bottles, excessive sugar intake and low-frequency toothbrushing and improper toothbrushing methods.

Unlike in some other studies [3, 11, 14, 17], this study did not find an association between the use of dental services, BMI overweight, being a single mother and maternal caries experience. After all, it may be useful to adopt an intervention approach, which considers underlying social determinants of dental health and utilizes a more clientcentred approach, such as motivational interviewing [6].

\section{Study strength and limitation}

This study was based on data from the prospective cohort study of Thai children (PCTC). Compared to a more traditionally designed study, this cohort study design with data collection at several time points during pregnancy and early childhood had the advantage to reduce recall bias [27]. Bias may have arisen in SECC and its social determinants between children who refused or were not present on the day for the dental examination (almost one-fourth of those who were recruited as pregnant women) and those children who were examined. It is known that children/parents refusing to participate may have higher caries prevalence than children who do participate in research studies, but it is probably no reason to assume that children who were not present at the day of examination differ from the participating children.

\section{Conclusion}

A very high prevalence of S-ECC was found among pre-school children in Northern Thailand. Several risk factors, including environmental factors (sub-optimal fluoridation of water supply, no schooling of mother of child, being male), and risk behaviour (sleeping with a bottle at 30 months) were identified as possible risk factors for the development of S-ECC, which can help guide the development of prevention programmes of $\mathrm{S}$ ECC for pre-school aged children.

\section{Abbreviations}

BMI: Body Mass Index; DFMS: Decayed, missing, and filled surfaces; DMFT: Decayed, missing and filled teeth; PCTC: Prospective Cohort Study of Thai children; S-ECC: Severe Early Childhood Caries.

\section{Competing interests}

The authors declare that they have no competing interests.

\section{Authors' contributions}

KP designed the study, analyzed the data and wrote the paper. AM contributed to the acquisition of the data, read and approved the manuscript. All authors read and approved the final manuscript.

\section{Acknowledgments}

We thank the families who participated in the study. The research was supported by the Thailand Research Fund, the Health System Research Institute of Thailand, the Ministry of Public Health of Thailand, and the WHO. The secondary analysis was supported by the Intercountry Centre for Oral Health, Chiang Mai, Thailand. The authors gratefully acknowledge Dr. Chanpen Chooprawon, Asst. Prof. Dr. Jariya Wittayasooporn, Dr. Gamon Satchaiyan, Dr. Sunsanee Rajchagool and the PCTC committee for their permission to use the datasets, Taksin Pimpak for her assistance in data management, and the academic coordinating person for this project, Ms. Numpueng Rattanapiboon.

\section{Author details}

${ }^{1}$ ASEAN Institute for Health Development, Madidol University, Salaya, Phutthamonthon 73170, Nakhonpathom, Thailand. 'Department of Psychology, University of the Free State, Bloemfontein 9300, South Africa. ${ }^{3}$ HIV/AIDS/STI/and TB (HAST), Human Sciences Research Council, Private Bag X41, Pretoria 0001, South Africa.

Received: 13 April 2015 Accepted: 9 September 2015

Published online: 14 September 2015

\section{References}

1. Losso EM, Tavares MC, Silva JY, Urban Cde A. Severe early childhood caries: an integral approach. J Pediatr. 2009;85:295-300.

2. Bissar A, Schiller P, Wolff A, Niekusch U, Schulte AG. Factors contributing to severe early childhood caries in south-west Germany. Clin Oral Investig. 2014;18:1411-8.

3. Folayan MO, Kolawole KA, Oziegbe EO, Oyedele T, Oshomoji OV, Chukwumah NM, et al. Prevalence, and early childhood caries risk indicators in preschool children in suburban Nigeria. BMC Oral Health. 2015;15(1):72. doi:10.1186/s12903-015-0058-y.

4. Nobile CG, Fortunato L, Bianco A, Pileggi C, Pavia M. Pattern and severity of early childhood caries in Southern Italy: a preschool-based cross-sectional study. BMC Public Health. 2014;14:206. doi:10.1186/1471-2458-14-206.

5. Slabsinskiene E, Milciuviene S, Narbutaite J, Vasiliauskiene I, Andruskeviciene $\checkmark$, Bendoraitiene EA, et al. Severe early childhood caries and behavioral risk factors among 3-year-old children in Lithuania. Medicina. 2010;46:135-41. 
6. Naidu R, Nunn J, Kelly A. Socio-behavioural factors and early childhood caries: a cross-sectional study of preschool children in central Trinidad. BMC Oral Health. 2013;13:30

7. Ismail Al, Lim S, Sohn W, Willem JM. Determinants of early childhood caries in low-income African American young children. Pediatr Dent. 2008:30:289-96.

8. Hashim R, Williams S, Thomson WM. Severe early childhood caries and behavioural risk indicators among young children in Ajman, United Arab Emirates. Eur Arch Paediatr Dent. 2011;12:205-10.

9. Azevedo TD, Bezerra AC, de Toledo OA. Feeding habits and severe early childhood caries in Brazilian preschool children. Pediatr Dent. 2005;27:28-33.

10. Leake J, Jozzy S, Uswak G. Severe dental caries, impacts and determinants among children 2-6 years of age in Inuvik Region, Northwest Territories, Canada. J Can Dent Assoc. 2008;74:519.

11. Turton BJ, Durward CS, Manton DJ. Early childhood caries and maternal caries experience in a convenience sample of Cambodian pre-schoolers. Pediatr Dental J. 2015;25:14-8.

12. Bhoomika W, Ramakrishna Y, Munshi AK. Relationship between severe early childhood caries and body mass index. J Clin Pediatr Dent. 2013;37:235-42.

13. Feldens CA, Giugliani ER, Vigo Á, Vítolo MR. Early feeding practices and severe early childhood caries in four-year-old children from southern Brazil: a birth cohort study. Caries Res. 2010;44:445-52.

14. Qin M, Li J, Zhang S, Ma W. Risk factors for severe early childhood caries in children younger than 4 years old in Beijing, China. Pediatr Dent. 2008;30:122-8.

15. Plutzer K, Keirse MJ. Influence of first-time mothers' early employment on severe early childhood caries in their child. Int J Pediatr. 2012;2012:820680. doi:10.1155/2012/820680

16. Chaffee BW, Feldens CA, Rodrigues PH, Vítolo MR. Feeding practices in infancy associated with caries incidence in early childhood. Community Dent Oral Epidemiol. 2015;43(4):338-48.

17. Evans EW, Hayes C, Palmer CA, Bermudez OI, Cohen SA, Must A. Dietary intake and severe early childhood caries in low-income, young children. J Acad Nutr Diet. 2013;113:1057-61.

18. Hallett KB, O'Rourke PK. Pattern and severity of early childhood caries. Community Dent Oral Epidemiol. 2006;34:25-35.

19. Hsieh HJ, Huang ST, Tsai CC, Hsiao SY. Toothbrushing habits and risk indicators of severe early childhood caries among aboriginal Taiwanese. Asia Pac J Public Health. 2012;26:238-47.

20. Data Archival for Maximum Utilization System (DAMUS). PCTC: Prospective Cohort Study of Thai Children, 2011. Retrieved at http://pctc.damus.in.th/ damus/. Accessed 10 July 2015.

21. Department of Health, Ministry of Public Health. Flouridated milk to prevent dental caries in Thailand, 2010. Retrieved from http://eng.anamai.moph.go.th/ main.php?filename $=03$ fmtpdc. Accessed 10 July 2015.

22. Peltzer K, Mongkolchati A, Satchaiyan G, Rajchagool S, Pimpak T. Sociobehavioral factors associated with caries increment: a longitudinal study from 24 to 36 months old children in Thailand. Int J Environ Res Public Health. 2014;11:10838-50.

23. World Health Organization. Oral health surveys: basic methods (4th ed). Geneva: World Health Organization, 1997. Retrieved at http://apps.who.int/ iris/handle/10665/41905\#sthash.nltBJXcl.dpuf. Accessed 20 March 2015.

24. Druny TF, Horowitz AM, Ismail Al, Maertens MP, Rozier RG, Selwitz RH. Diagnosing and reporting early childhood caries for research purposes. A report of a workshop sponsored by the National Institute of Dental and Craniofacial Research, the Health Resources and Services Administration, and the Health Care Financing Administration. J Public Health Dent. 1999;59(3):192-7.

25. Thitasomakul S, Thearmontree A, Piwat S, Chankanka O, Pithpornchaiyakul W, Teanpaisan R, et al. A longitudinal study of early childhood caries in 9-to 18month-old Thai infants. Community Dent Oral Epidemiol. 2006;34:429-36.

26. Sutthavong S, Taebanpakul S, Kuruchitkosol C, Ayudhya TI, Chantveerawong T, Fuangroong S, et al. Oral health status, dental caries risk factors of the children of public kindergarten and schools in Phranakornsriayudhya, Thailand. J Med Assoc Thai. 2010;93 Suppl 6:S71-8.

27. Rothman KJ, Greenland S, Lash TL. Modern epidemiology. 3rd ed. Philadelphia, PA: Lippincott, Williams \& Wilkins; 2008.

\section{Submit your next manuscript to BioMed Central and take full advantage of:}

- Convenient online submission

- Thorough peer review

- No space constraints or color figure charges

- Immediate publication on acceptance

- Inclusion in PubMed, CAS, Scopus and Google Scholar

- Research which is freely available for redistribution

Submit your manuscript at www.biomedcentral.com/submit 